\title{
Relationship between Mechanical Neck Pain and Dorsal Hyperkyphosis
}

\author{
EMAN M.A. TANTAWY, M.Sc.*; NADIA A. FAYAZ, Ph.D.**; KARIMA A. HASSAN, Ph.D.** and \\ AHMED H.E. AZZAM, Ph.D.***
}

The Department of Physical Therapy, National Medical Institute, Damanhour*, The Department of Physical Therapy for Musculoskeletal Disorders, Faculty of Physical Therapy** and Orthopedic Surgery, Faculty of Medicine ${ }^{* * *}$, Cairo University, Egypt

\begin{abstract}
Background: Dorsal hyperkyphosis is a condition indicated by the abnormal increase in the curvature convexity of the thoracic vertebral column. The neck pain is a common clinical complaint that commonly seen at physiotherapy clinics all over the world. In order to properly prevent or treat a clinical problem, potential risk factors need to be identified.
\end{abstract}

Aim of the Study: The purpose of this study was to investigate the correlation between thoracic hyperkyphosis and cervical ROM, neck pain and functional abilities of the neck.

Subjects and Methods: Sixty subjects diagnosed as mechanical neck pain with dorsal hyperkyphosis of both sexes participated in this study. Their ages ranged from 20 to 40 years. Agreement of the Ethical Committee of Faculty of Physical Therapy was obtained before beginning of the study, degree of hyerkyphosis was measured by gravity dependent inclinometer, assessment of cervical range of motion was performed by the researcher via using OB Myrien inclinometer, VAS scale was used for assessment of neck pain, and NDI was used for assessment of neck disabilities.

Results: There was a statistical significant positive correlation between degree of hyperkyphosis and neck pain, there was a statistical significant negative correlation between degree of hyperkyphosis and neck extension, there was no correlation between degree of hyperkyphosis and neck disabilities and there was no correlation between degree of hyperkyphosis and neck flexion, side bending and neck rotation.

Conclusion: Degree of dorsal hyperkyphosis could affect the severity of neck pain and could decrease the mobility of the neck in the extention range of motion. On the other side degree of dorsal hyperkyphosis couldn't affect neck abilities and the mobility of the neck in the other directions.

Key Words: Dorsal hyperkyphosis - Mechanical neck pain.

Correspondence to: Dr. Eman M.A. Tantawy, The Department of Physical Therapist, National Medical Institute, Damanhour, Egypt

\section{Introduction}

DORSAL (thoracic) hyperkyphosis is the excessive curvature of the thoracic spine, commonly described as the dowager's hump or gibbous deformity. Increased thoracic hyperkyphosis, a common age-related postural change, is evident in older adults and may pose significant health risk. Reports of prevalence and incidence of hyperkyphosis in older adult vary from approximately $20 \%$ to $40 \%$ among both men and women [1-3] .

Mechanical neck pain is most commonly defined as pain located in the cervical spine or cervicothoracic junction that is elicited and/or exacerbated by cervical motion and/or palpation of cervical musculature $[4,5]$. Mechanical neck pain can result from poor or faulty posture, overuse injuries or trauma. However, in most patients neck pain is not due to a serious disease but rather to postural or mechanical factors. It is then commonly referred to as simple or non-specific neck pain [6]

As the different sections of the spinal column are interlinked and one region exerts an influence over another, a low range of motion (hypomobility) in the thoracic spine is an indicator of neck pain, and alterations in the cervical spine can occur due to dysfunctions of the thoracic spine $[\mathbf{7 , 8 ]}$. The cervical spine is a common site of pain that may arise from different parts of the upper limbs or dysfunctions of the upper thoracic spine [9] .

Clinical sagittal plane assessment of the thoracic kyphosis angle is considered an essential component of the postural examination of patients presenting with upper body pain syndromes. Cervical headaches and conditions involving the shoulder, such as subacromial pain syndrome, have all been 
associated with an increase in the thoracic kyphosis. Concomitantly a decrease in the thoracic kyphosis as a result of a stretching and strengthening rehabilitation programme is believed to be associated with a reduction in symptoms and pain and improvement in function [10]. The purpose of this study was to investigate the correlation between thoracic hyperkyphosis and cervical ROM, neck pain and functional abilities of the neck in patients with mechanical neck pain.

\section{Patients and Methods}

Upon approval of Cairo University's supreme council of postgraduate studies and research, sixty subjects referred by orthopedic surgeons as mechanical neck pain with dorsal hyperkyphosis participated in this study. Their ages ranged from 20 to 40 years. The inclusion criteria were: They had dorsal hyperkyphosis, and they had no any arthritic diseases in the neck or the thoracic curve. Exclusion criteria were: A history of any of the following condition: inflammatory or osteometabolic diseases or any congenital disorders and rheumatic disorders, a history of neurological diseases, a history of vertebral fractures and surgical spinal fixation, and for female subjects pregnancy or suspicion of pregnancy.

This study was conducted at the outpatient clinic of Damanhur Medical National Institute, ElRahmaniya Central Hospital and Yonis Mosque Outpatient Clinic. Beheira, Egypt. The study extended from October 2016 to May 2017.

\section{Procedures:}

Each subject was examined by the researcher for the inclusive and exclusive criteria. The first step in procedure was related to assessing the degree of dorsal hyperkyphosis. The second step was related to assessing the cervical spine in the items of cervical mobility, severity of neck pain and neck disabilities.

1- The thoracic kyphosis was measured using two gravity dependent inclinometers. As depicted in, the feet of the inclinometers was placed over the spinal processes thought to correspond with the ${ }^{1 \mathrm{st}}$ and 2 nd thoracic spines (T1/2), and, over the 12 th thoracic and ${ }^{1 \text { st }}$ lumbar spines (T 12/L 1). These spinal levels were determined by palpation.

Prior to measuring spinal angles, participants were asked to stand with their feet either side of a spot marked on the floor (to ensure standardisation of subject position between measures) and adopted a comfortable standing position that felt natural to them. To achieve this, subjects were requested to swing their arms gently backward and forward 3 times by their sides and stop in a position that felt natural and comfortable to them; to flex and extend their head 3 times gently and stop in a position that felt natural and comfortable to them; and to take 3 breaths and adopt a position that felt natural and comfortable to them. These identical instructions were given to each subject prior to each data collection period. Once this posture had been achieved $6 \mathrm{~mm}$ diameter adhesive markers were placed over $\mathrm{T} 1$ and $\mathrm{T} 2$, and $\mathrm{T} 12$ and $\mathrm{L} 1$. These levels were identified as follows.

The spinous process of the 5 th lumbar spine was identified above the sacrum and the L1 and T12 spinous processes was identified and marked by palpating superiorly from this reference point. The 7 th cervical vertebra was designated to have the most prominent spinal process. Palpating inferiorly from this reference point the $\mathrm{T} 1$ and $\mathrm{T} 2$ spinous processes was identified and marked. Once identified subjects were again requested to adopt a posture that felt natural to them and the inclinometers was placed as simultaneously as possible over the markers. Inclinometer measurements was performed 3 times in succession as shown in Fig. (1).

2- The subjects comfortably seated for measuring the neck mobility, the goniometer was affixed to the head with the aid of a Velcro strap. For flexion and extension motions, the goniometer was affixed directly above the earlobe while for side bending motions; it was affixed to the forehead. For the rotation motions, the goniometer was positionedat the vertex of the head the subjects trunk was fastened to the chair to prevent movement of the thoracolumber spine during the neck flexion movement as shown in Figs. (2-4).

3- Patients were simply asked to show their pain level between the two end points of the line. The line was generally 10 to $15 \mathrm{~cm}$ in length, because studies had shown this length was the easiest for patient use and it resulted in the smallest measurement error. The distance from the "no pain" end point represented the patient's pain score all participants completed the VAS by indicating the average pain level.

4- All patients received a verbal description of how to fill in NDI and then were instructed to choose only one answer that most closely suited their condition at the present time. The score of each item varied between 0 (no pain and no functional limitation) and 5 (worst pain and maximal limitation) resulting in a total score of 0 (no disability) to 50 (totally disabled) (Appendix). 


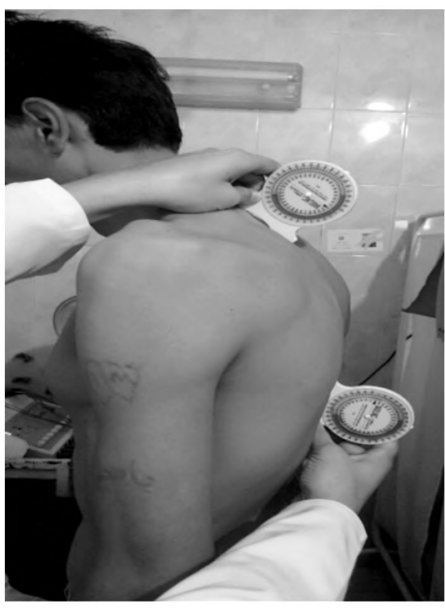

Fig. (1): Hyperkyphosis assessment.
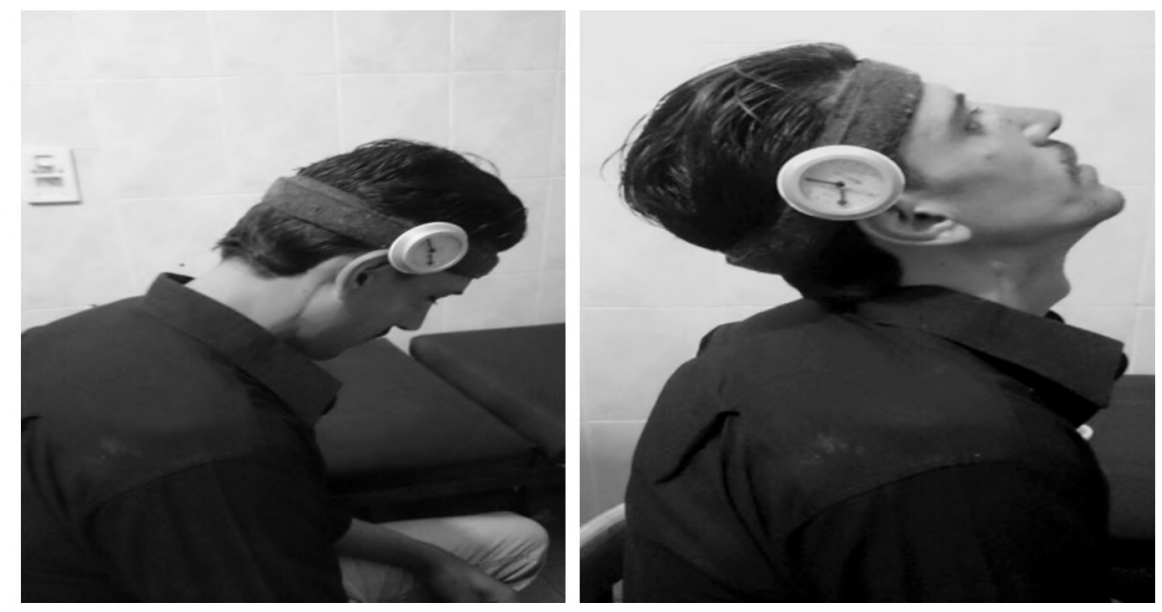

Fig. (2): Assessment of cervical flexion and extension ROM.
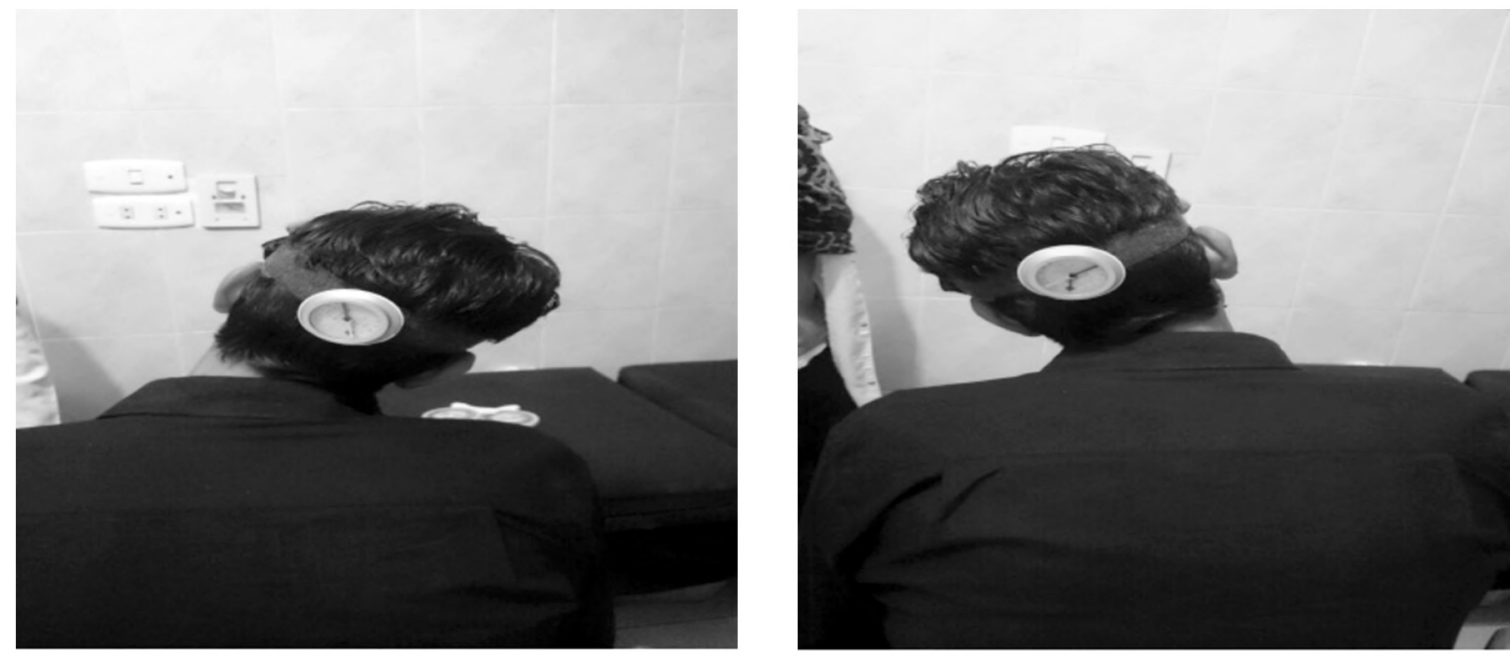

Fig. (3): Assessment of cervical right and left ROM.
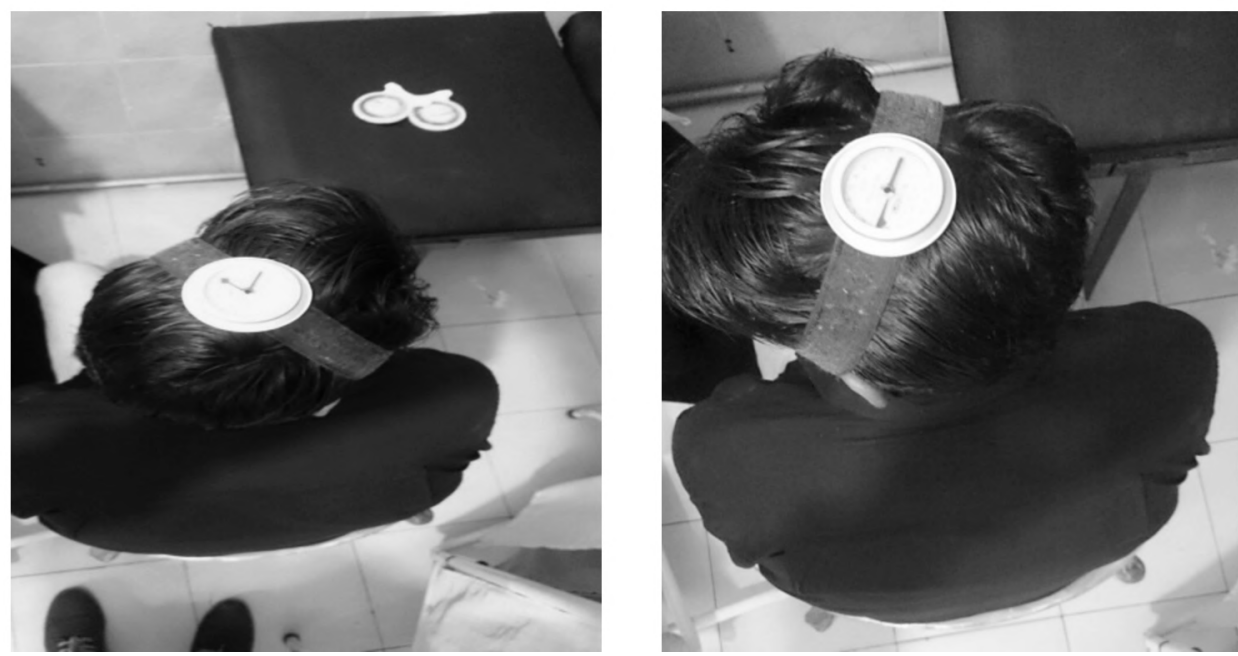

Fig. (4): Assessment of cervical right and left ROM. 


\section{Results}

Statistical analysis was conducted using SPSS for windows, Version 22 SPSS, Inc., Chicago, IL). Prior to final analysis, data were screened for normality assumption and presence of extreme scores. This exploration was done as a pre-requisite for parametric calculations of the analysis of difference. Descriptive analysis using histograms with the normal distribution curve showed that the kyphosis angle and ROM of cervical flexion, extension, right, and left side bending and rotation, VAS, and NDI were not normally distributed and violates the parametric assumption for the measured dependent variable. Normality test of data using Shapiro-Wilk test was used, that reflect the data was not normally distributed for all most dependents variables. Spearman product moment correlation coefficient was used to determine the correlations among the kyphosis angle and ROM of cervical flexion, extension, right, and left side bending and rotation, VAS, and NDI. The initial alpha level for the correlation analysis was set at 0.05 .

Correlation among the kyphosis angle and ROM of cervical flexion, extension, right, and left side bending and rotation, $V A S$, and NDI:

As presented in (Table 1) the correlations among the kyphosis angle and ROM of cervical flexion, extension, right, and left side bending and rotation, VAS, and NDI were studied through the Spearman product moment correlation coefficient. It revealed that there was no correlation between kyphosis angle and ROM of cervical flexsion ( $\pi=0.145$, $p=0.283$ ). While, there was weak negative significant correlation between kyphosis angle and ROM of cervical extension ( $\pi=-0.308, p=0.02$ ). Additionally, there was no correlation between kyphosis angle and ROM of cervical right side bending ( $\pi=$ $.258, p=0.053)$, between kyphosis angle and ROM of cervical left side bending ( $\pi=-0.194, p=0.149$ ), between kyphosis angle and ROM of cervical right rotation ( $\pi=-0.096, p=0.476)$, between kyphosis angle and ROM of cervical left rotation $(\pi=0.241$, $p=0.071$ ), there was weak positive correlation between kyphosis angle and VAS $(\pi=0.316, p=$ $0.017 *)$, there was no correlation between kyphosis angle and NDI ( $\pi=0.036, p=0.79)$ (as shown in Figs. (5-12).

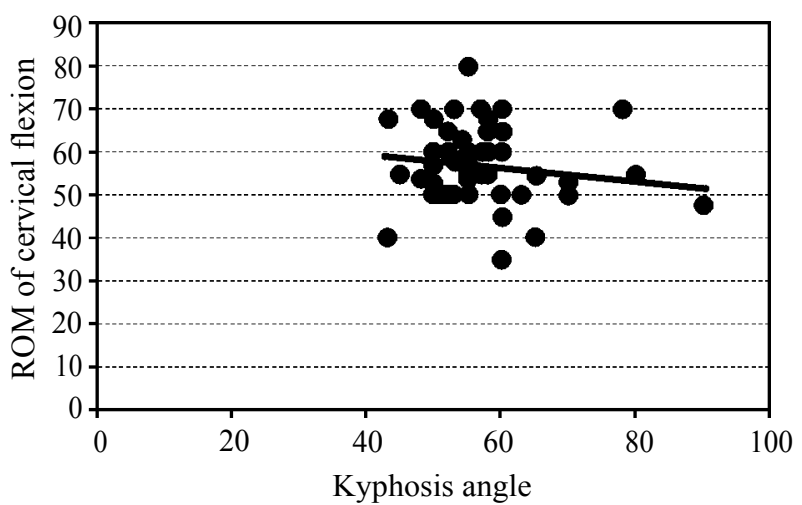

Fig. (5): Scatter plot for the bivariate correlation between kyphosis angle and ROM of cervical flexion.

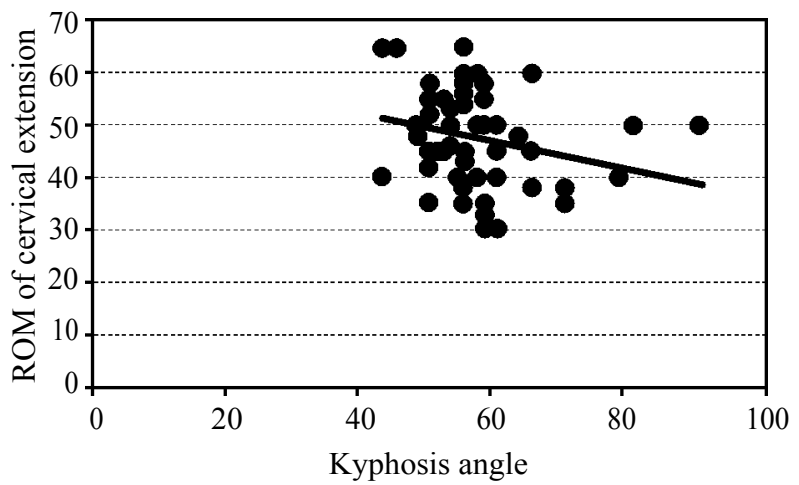

Fig. (6): Scatter plot for the bivariate correlation between kyphosis angle and ROM of cervical extension.

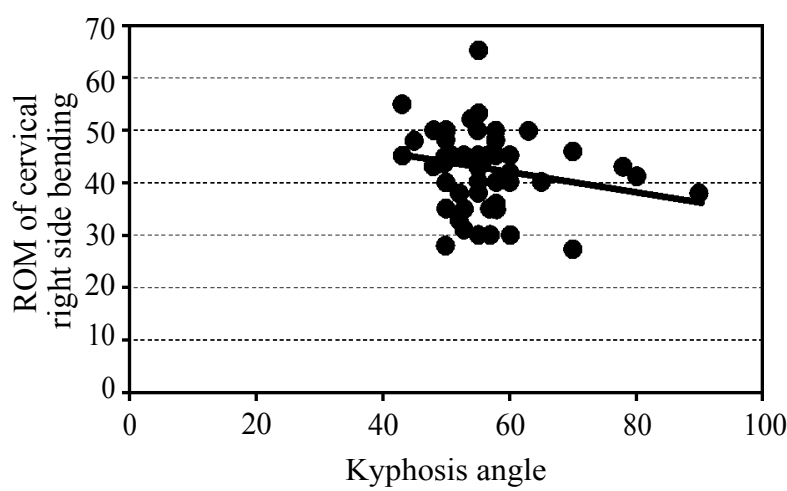

Fig. (7): Scatter plot for the bivariate correlation between kyphosis angle and ROM of cervical right bending.

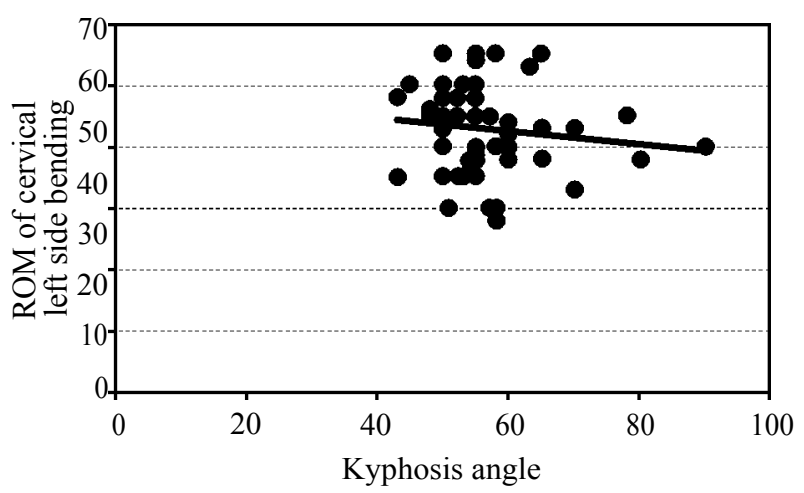

Fig. (8): Scatter plot for the bivariate correlation between kyphosis angle and ROM of cervical left bending. 


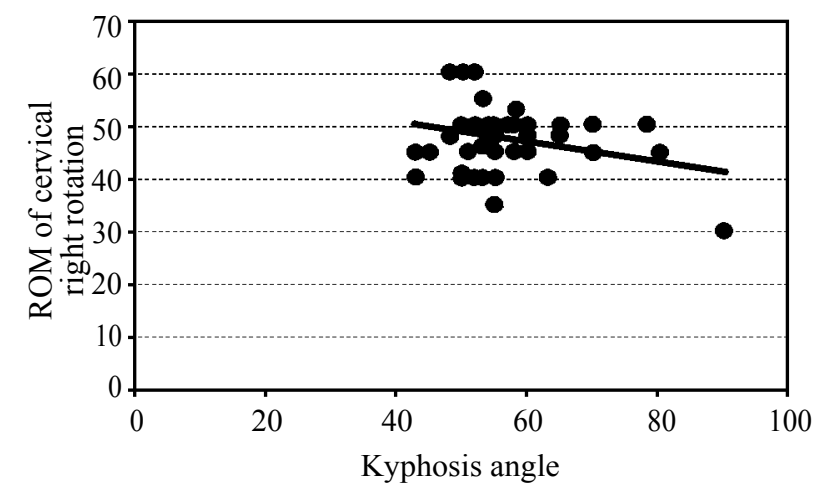

Fig. (9): Scatter plot for the bivariate correlation between kyphosis angle and ROM of cervical right rotation.

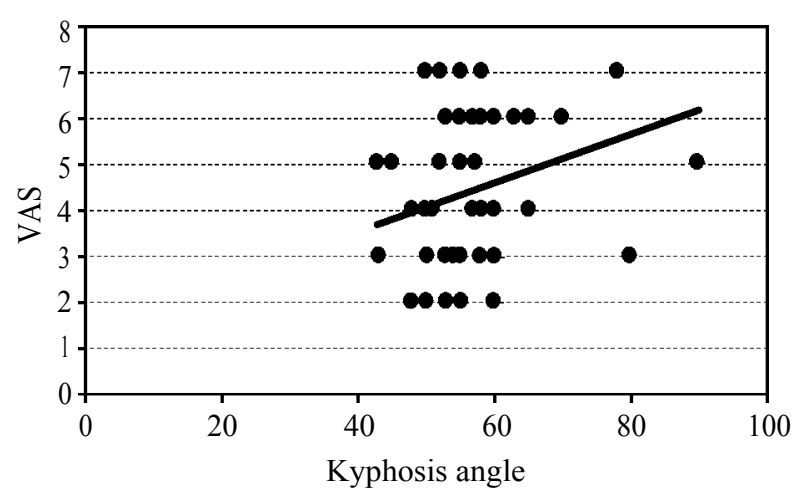

Fig. (11): Scatter plot for the bivariate correlation between kyphosis angle and VAS.

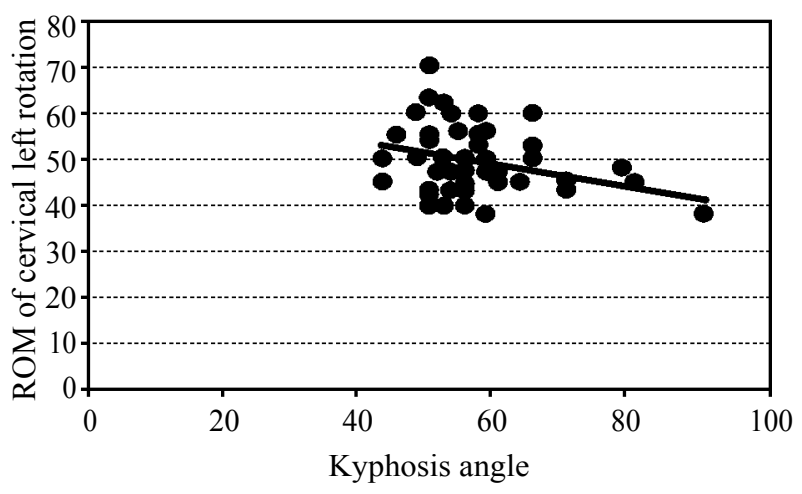

Fig. (10): Scatter plot for the bivariate correlation between kyphosis angle and ROM of cervical left rotation.

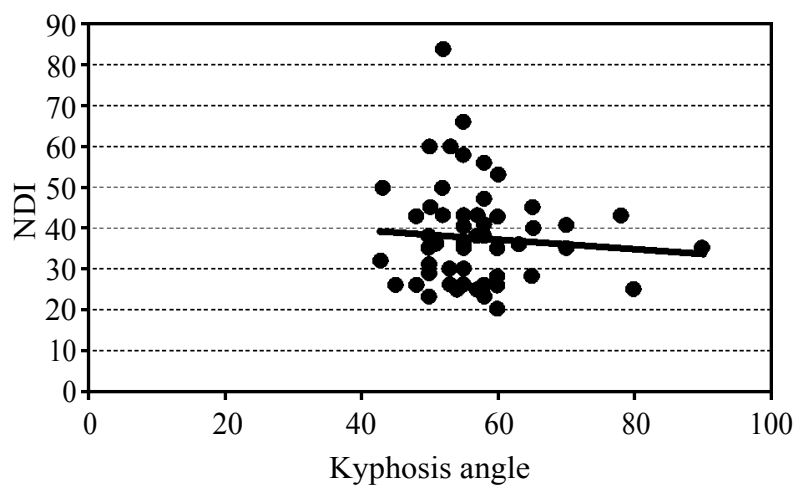

Fig. (12): Scatter plot for the bivariate correlation between kyphosis angle and NDI.

Table (1): Bivariate correlations among the kyphosis angle and ROM of cervical flexion, extension, right, and left side bending and rotation, VAS, and NDI.

\begin{tabular}{|c|c|c|c|c|c|c|c|c|}
\hline & $\begin{array}{l}\text { ROM of } \\
\text { cervical } \\
\text { flexion }\end{array}$ & $\begin{array}{l}\text { ROM of } \\
\text { cervical } \\
\text { extension }\end{array}$ & $\begin{array}{c}\text { ROM of } \\
\text { cervical right } \\
\text { side bending }\end{array}$ & $\begin{array}{c}\text { ROM of } \\
\text { cervical left } \\
\text { side bending }\end{array}$ & $\begin{array}{l}\text { ROM of } \\
\text { cervical } \\
\text { right rotation }\end{array}$ & $\begin{array}{c}\text { ROM of } \\
\text { cervical } \\
\text { left rotation }\end{array}$ & VAS & NDI \\
\hline $\begin{array}{l}\text { - Kyphosis } \\
\text { angle }\end{array}$ & $\begin{array}{l}\rho=0.145 \\
p=0.283\end{array}$ & $\begin{array}{l}\rho=0.3 .8 \\
p=0.02 *\end{array}$ & $\begin{array}{l}\rho=0.258 \\
p=0.053\end{array}$ & $\begin{array}{l}\rho=0.194 \\
p=0.149\end{array}$ & $\begin{array}{l}\rho=0.096 \\
p=0.476\end{array}$ & $\begin{array}{l}\rho=0.241 \\
p=0.071\end{array}$ & $\begin{aligned} \rho & =0.316 \\
p & =0.017 *\end{aligned}$ & $\begin{array}{l}\rho=-0.036 \\
p=0.79\end{array}$ \\
\hline
\end{tabular}

*: Significant at alpha level 0.05

$p$ : Probability value.

$\rho$ : Spearman correlation.

\section{Discussion}

The main purpose of this study was to investigate the relationship between thoracic hyperkyphosis (degree of the thoracic curve) and mechanical neck pain (pain intensity, cervical range of motion and neck dysfunction) in subjects with dorsal hyperkyphosis.

\section{Dorsal hyperkyphosis and neck pain:}

In support to the present study Nejati et al., [11] in a cross-sectional study to explore the relationships between neck pains, sagittal postures of cervical and thoracic spine and shoulders among office workers in two positions, straight looking forward and working position. They showed that forward head posture and thoracic kyphosis were accompanied by neck pain.

The findings of present study have been supported by the work of Kenmoku et al., [12] who examined the relationship between sagittal spinal alignment and chronic neck and shoulder pain and to classify the location of the pain in younger individuals. They showed that thoracic kyphosis and lumbar lordosis were related to chronic neck and shoulder pain. Mean thoracic kyphosis and mean lumber lordosis of pain group were significantly larger than those of normal. In particular, in terms of neck pain and pain above the scapula, 
thoracic kyphosis increased in subjects with symptoms significantly.

On the same line the work of Lau et al., [13] to investigate the relationship between posture of thoracic spin and neck pain. They investigated the relationships among the sagittal postures of the thoracic and cervical spine, presence of neck pain, neck pain severity, and disability. Subjects with neck pain showed a significant greater upper thoracic angle (7.34) than those without neck pain. Moreover, the upper thoracic angle was positively correlated with the presence of neck pain $(r=0.63)$. So patients with cervical dysfunction had significantly greater thoracic kyphosis compared to healthy controls, and thoracic kyphosis was significantly associated with neck pain. The result of present study agree with the result of Lau et al., [13], although they selected subjects with neck pain and control group but in the present study there was no control group.

Findings of present study regarding thoracic hyperkyphosis and neck pain agree with the work of Kaya and Celenary [14] who investigated the degree of thoracic spinal curvature and mobility in subjects with and without Chronic Neck Pain (CNP), cut-off points, and the relationship with pain. They concluded that patients with CNP showed greater sagittal thoracic curvature and lower thoracic mobility than those without CNP, Sagittal thoracic curvature was positively correlated with neck pain, while thoracic mobility was negatively correlated with neck pain and an increase in thoracic curvature of more than $45^{\circ}$ and a decrease in mobility more than $30^{\circ}$ may be critical for CNP patients, but in present study no measure the thoracic mobility.

The results of the present study disagree with the work of Poussa et al., [15] who studied anthropometric measurements for their associations with the incidence of neck pain in a population study of 430 children who were examined five times: At the age 11-14 and 22 years. Body height, weight and the degrees of trunk asymmetry (thoracic kyphosis and lumbar lordosis) were measured at every examination. No measure of spinal sagittal posture or trunk asymmetry predicted the incidence of neck pain. Anthropometric measurements other than body height were not found to predict neck pain. Selecting younger age and the long duration of the study might be the causes of contradiction.

Dorsal hyperkyphosis and cervical range of motion:

Findings of present study regarding thoracic hyperkyphosis and Cervical Range of Motion
(CROM) agree with work by Shah and Varghese [16] that there was no significant correlation between Forward head posture, Thoracic Kyphosis and CROM of adults with and without Cervical spine dysfunction.

The results of the present study disagree with the work of Fujimori et al., [17] who examined the relationship between cervical degeneration and spinal alignment by comparing patients with adult spinal deformity versus the control cohort. They concluded that cervical lordosis could increase as a compensatory reaction against sagittal imbalance or hyperthoracic kyphosis. These results suggested that the cervical spine has a large capacity to respond to a variety of changes in alignment. But we concluded that a decrease of cervical extension (decreased cervical lordosis) as a compensatory reaction against hyperkyphosis.

Findings of the present study disagree with the work of Quek [18] their chief finding was the indirect effects of Forward Head Posture (FHP) on the relation between exaggerated thoracic kyphosis and reduced cervical ROM. This study showed that in a group of older adults, thoracic kyphosis had an indirect effect on cervical ROM through a FHP. Increased kyphosis was associated with a greater FHP, and a greater FHP, in turn, was associated with decreased cervical flexion and general cervical rotation but not with upper cervical rotation.

However our results (insignificant correlation) contradicted that obtained in the above study for the hyperkyphosis of adults. Methodologic and analytical differences as well as younger mean age of participants could be the reason for the contrary results.

Reduced mobility at the cervical-thoracic junction has been shown to be a risk factor for neck pain. This relationship was further explored by Fernandez-de-la-Peñas et al., [19] who identified Upper Thoracic (UT) joint dysfunctions in patients experiencing cervical whiplash $(69 \%)$ and mechanical neck pain (13\%).

The results of present study are supported by Young et al., [20] state that there is a significant amount of evidence to recommend thoracic manipulation for the treatment of mechanical neck pain, especially for short-term improvement of range of motion and disability.

Most of the studies focused on the importance of treatment of the dorsal and cervical regions based on the biomechanical bases. The present 
study tried to clear the rule of assessment. There were a few researches worked on assessment. Also in our study there was no control group, for these reasons the comparison with the results of other studies was a little bit difficult and had some contradicts.

The biomechanical link between the cervical spine and the thoracic spine suggest that disturbances in joint mobility in the thoracic spine may serve as an underlying contributor to the development of neck disorders. In addition, it has been demonstrated that a significant association exists between decreased mobility of the thoracic spine and the presence of patient-reported complaints associated with neck pain as shown by Nordgren and Norlander [21]

The results of the present study disagree with that of Kall [22] in a longitudinal study to investigate the distribution of segmental flexion mobility in the cervico-thoracic spine of men and women with whiplash-associated disorders the data was obtained from a previous trial on 47 patients. For assessment a cervical range of motion instrument, the cervicothoracic ratio and visual analog scale were used. They found no significant correlation between the relative segmental flexion mobility at different segments and future neck pain, i.e. hypomobility in the segment c7-t1 did not imply a significant increased risk for future neck pain.

\section{Dorsal hyperkyphosis and neck disabilities:}

Fioco et al., [23] identified the relationship between postural imbalance and cervical disability in visually impaired individuals. The postural assessment was performed by means of photogrammetry associated with the Neck Disability Index (NDI). Individuals with visual impairment promote postural adjustments in head positioning, increase in dorsal kyphosis and other postural deformities. They found that the postural problem was not associated with the occurrence of disability and the postural problem that could lead to neck pain didn't interfere with the subject's disability. They investigated the relationships among the sagittal postures of the thoracic and cervical spine, presence of neck pain, neck pain severity, and disability.

Results of the present study disagree with that of Lau et al., [13] who investigated the relationships among the sagittal postures of the thoracic and neck disability. They demonstrated that the upper thoracic angle was positively correlated with The Northwick Park Neck Pain Questionnaire (NPQ) $(r=0.44)$. Therefore, the greater the upper thoracic angle, the higher the NPQ scores and vice versa.
So the sagittal posture of thoracic spine was one of the dimensions in addressing the neck disability.

UP to auther's knowledge little was known about the mediating mechanisms linking thoracic kyphosis to neck dysfunctions. And yet, understanding these mechanisms was important for refining and developing more targeted and efficient interventions for patients with dorsal hyperkyphosis to avoid neck dysfunctions.

\section{Conclusion:}

Based on the scope and findings of this study, it could be concluded that the degree of dorsal hyperkyphosis could affect the severity of neck pain and could decrease the mobility of the neck in the extention range of motion. Also it could be concluded that the degree of dorsal hyperkyphosis couldn't affect the other five cervical range of motions and the neck disabilities.

\section{References}

1- TRAN T.H., WING D., DAVIS A., BERGSTROM J., SCHOUSBOE J.T., NICHOLS J.F., et al.: Correlations among four measures of thoracic kyphosis in older adults. Osteoporos. Int., 27: 1255-9, 2016.

2- KADO D.M., HUANG M.H., KARLAMANGLA A.S., BARRETT-CONNOR E., GREENDALE G.A.: Hyperkyphotic posture predicts mortality in older communitydwelling men and women: A prospective study. J. Am. Geriatr. Soc., 52: 1662-7, 2004.

3- TAKAHASHI T., ISHIDA K., HIROSE D., NAGANO Y., OKUMIYA K., NISHINAGA M., et al.: Trunk deformity is associated with a reduction in outdoor activities of daily living and life satisfaction in community-dwelling older people. Osteoporos. Int., 16 (3): 273-9, 2005.

4- CROSS K.M., KUENZE C., GRINDSTAFF T.L. and HERTEL J.: Thoracic spine thrust manipulation improves pain, range of motion, and selfreported function in patients with mechanical neck pain: A systematic review. J. Orthop. Sports Phys. Ther., 41: 633-42, 2011.

5- CLELAND J.A., CHILDS J.D., McRAE M., PALMER J.A. and STOWELL T.: Immediate effects of a thoracic manipulation in patients with neck pain: A randomized clinical trial. Man. Ther., 10: 127-35, 2005.

6- BINDER A.: The diagnosis and treatment of nonspecific neck pain and whiplash. Europa Medicophysica, 43 (1): 79-89, 2007.

7- CLELAND J.A., CHILDS J.D., FRITZ J.M., WHITMAN J.M. and EBERHART S.L.: Development of a clinical prediction rule for guiding treatment of a subgroup of patients with neck pain: Use of thoracic spine manipulation, exercise, and patient education. Phys. Ther., 87: 923, 2007.

8- LAU H.M.C., CHIU T.T.W. and LAM T.H.: The effectiveness of thoracic manipulation on patients with chronic mechanical neck pain: A randomized controlled trial. Man. Ther., 16: 141-7, 2011. 
9- DUTTON M.: Orthopaedic Physical Therapy: Examination, Evaluation Intervention, ed. New York: McGrawHill Medical Publishing Division, 2010.

10-LEWIS J.S. and VALENTINE R.E.: Clinical measurement of the thoracic kyphosis: A study of the intra-rater reliability in subjects with and without shoulder pain. B.M.C. Musculoskelet. Disord., 11: 39, 2010.

11- NEJATI P., LOTFIAN S., MOEZY A., MOEZY A. and NEJATI M.: The relationship of forward head posture and rounded shoulders with neck pain in Iranian office workers. Med. J. Islam. Repub., 28: 26, 2014.

12- KENMOKU T., SUZUKI T., OCHIAI N., EBATA T., MIYAJIMA G. and NAGURA N.: The Relationship between Neck and Shoulder Pain and the Sagittal Alignment of the Spine in Standing in Younger Generation. Open Journal of Orthopedics, 5: 337-44, 2015.

13- LAU K.T., CHEUNG K.Y., CHAN K.B., CHAN M.H., LO K.Y. and CHIU T.T.: Relationships between sagittal postures of thoracic and cervical spine, presence of neck pain, neck pain severity and disability. Man. Ther., 15 (5): 457-62, 2010.

14- KAYA D.O. and ÇELENAY S.T.: An investigation of sagittal thoracic spinal curvature and mobility in subjects with and without chronic neck pain: Cut-off points and pain relationship. Turkish Journal of Medical Sciences, 47: 891-6, 2017.

15- POUSSA M.S., HELIO“VAARA M.M., SEITSAMO J.T., KÖNÖNEN M.H., HURMERINTA K.A. and NISSINEN M.J.: Predictors of neck pain: A cohort study of children followed-up from the age of 11 to 22 years. Eur. Spine J., 14: 1033-6, 2005.

16- SHAH V. and VARGHESE A.: Association between thoracic kyphosis, head posture and cervical range of motion in adults with and without cervical spine dysfunction. Int. J. Sports Phys. Ther., 3 (5): 637-42, 2016.

17- FUJIMORI T., Le H., SCHAIRER W., INOUE S., IWASAKI M., ODA T. and HU S.: The relationship between cervical degeneration and spinal alignment by comparing patients with adult spinal deformity. Clin. Spine Surg., 30: 423-9, 2017.

18- QUEK J.: Effects of thoracic kyphosis and forward head posture on cervical range of motion in older adults. Manual Terapy; 18 (1): 65-71, 2013.

19- FERNANDEZ-De-La-PEÑAS C., FERNANDEZCARNERO J., FERNANDEZ A.P., LOMAS-VEGA R. and MIANGOLARRA-PAGE J.C.: Dorsal manipulation in whiplash injury treatment: A randomized controlled trial. J. Whiplash. Related Disorders, 3: 55-72, 2004.

20- YOUNG J.L., WALKER D., SNYDER S. and DALY K.: Thoracic manipulation versusmobilization in patients with mechanical neck pain: A systematic review. J. Man. Manip. Ther., 22: 141-53, 2014.

21- NORLANDER S. and NORDGREN B.: Clinical symptoms related to musculoskeletal neck-shoulder pain and mobility in the cervico-thoracic spine. Scand. J. Rehabil. Med., 30: 243-51, 1998.

22- KALL L.B.: Assessment of motion in the cervico-thoracic spine in patients withsubacute whiplash-associated disorders. J. Rehabil. Med., 40: 418-25, 2008.

23- FIOCO E.M., VERRI E.D., ZANELLA C.A.B., BIDURIN C.P. and TONELLO M.G.M.: Relationship between postural imbalance and cervical disability in visually impaired individuals. Rev. Bras. Promoç. Saúde., 29 (4): 525-32, 2016.

\title{
العلاقة بين آلم الرقبة الميكانيكى وزيادة التحلدب الصلدىى
}

\author{
الفرض من هذه الدراسة التحقق من وجود آى علاقة بين آلم الرقبة الميكانيكى وفرط التحدب الصدرى.

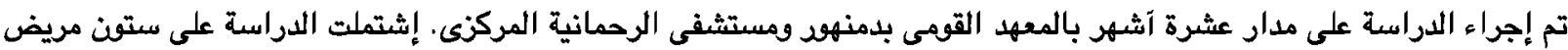

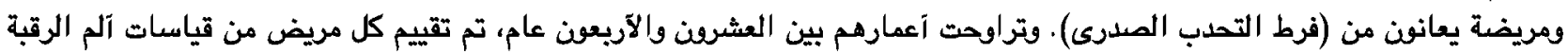

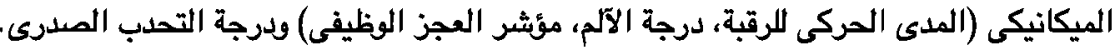

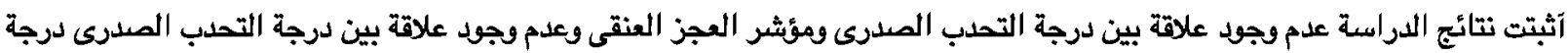

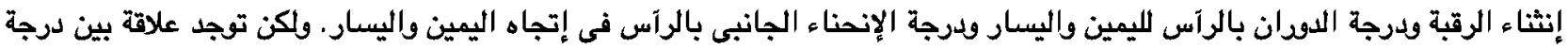

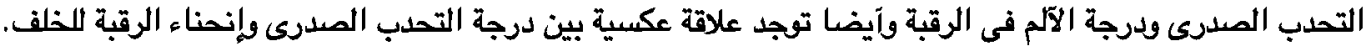




\section{Appendix}

\section{Neck Disability Index}

This questionnaire has been designed to give us information as to how your neck pain has affected your ability to manage in everyday life. Please answer every section and mark in each section only the one box that applies to you. We realise you may consider that two or more statements in any one section relate to you, but please just mark the box that most closely describes your problems.

Office Use Only
Name
Date

\section{Section 1: Pain Intensity}

I have no pain at the moment

- The pain is very mild at the moment

- The pain is moderate at the moment

The pain is fairly severe at the moment

- The pain is very severe at the moment

a The pain is the worst imaginable at the moment

\section{Section 2: Personal Care (Washing, Dressing, etc.)}

I I can look after myself normally without causing extra pain

- I can look after myself normally but it causes extra pain

$\square$ It is painful to look after myself and I am slow and careful

- I need some help but can manage most of my personal care

- I need help every day in most aspects of self care

I do get dressed, I wash with difficulty and stay in bed

\section{Section 3: Lifting}

I I can lift heavy weights without extra pain

I I can lift heavy weight but it gives extra pain

- Pain prevents me lifting heavy weights off the floor, but I can manage if they are conveniently placed, for example on a table

- Pain prevents me from lifting heavy weights but I can manage light to medium weights if they are conveniently positioned

I can only lift very light weights

I cannot lift or carry anything

\section{Section 4: Reading}

I can read as much as I want to with no pain in my neck

I can read as much as I want to with slight pain in my neck

I can read as much as I want to with moderate pain in my neck

n I can read as much as I want because of moderate pain in my neck

I can hardly read at all because of severe pain in my neck

I cannot read at all

\section{Section 5: Headaches}

I have no headaches at all

I I have slight headaches, which come infrequently

I I have moderate headaches, which come infrequently

- I have moderate headaches, which come frequently

n I have severe headaches, which come frequently

$\Pi$ I have headaches almost all the time

\section{Section 3: Lifting}

I I can concentrate fully when I want to win no difficulty

- I can concentrate fully when I want to win slight difficulty

$\Pi$ I have a fair degree of difficulty in concentrating when I want to

I I have a lot of difficulty in concentrating when I want t0

I have a great deal of difficulty in concentrating when I want to

I cannot concentrate at all 


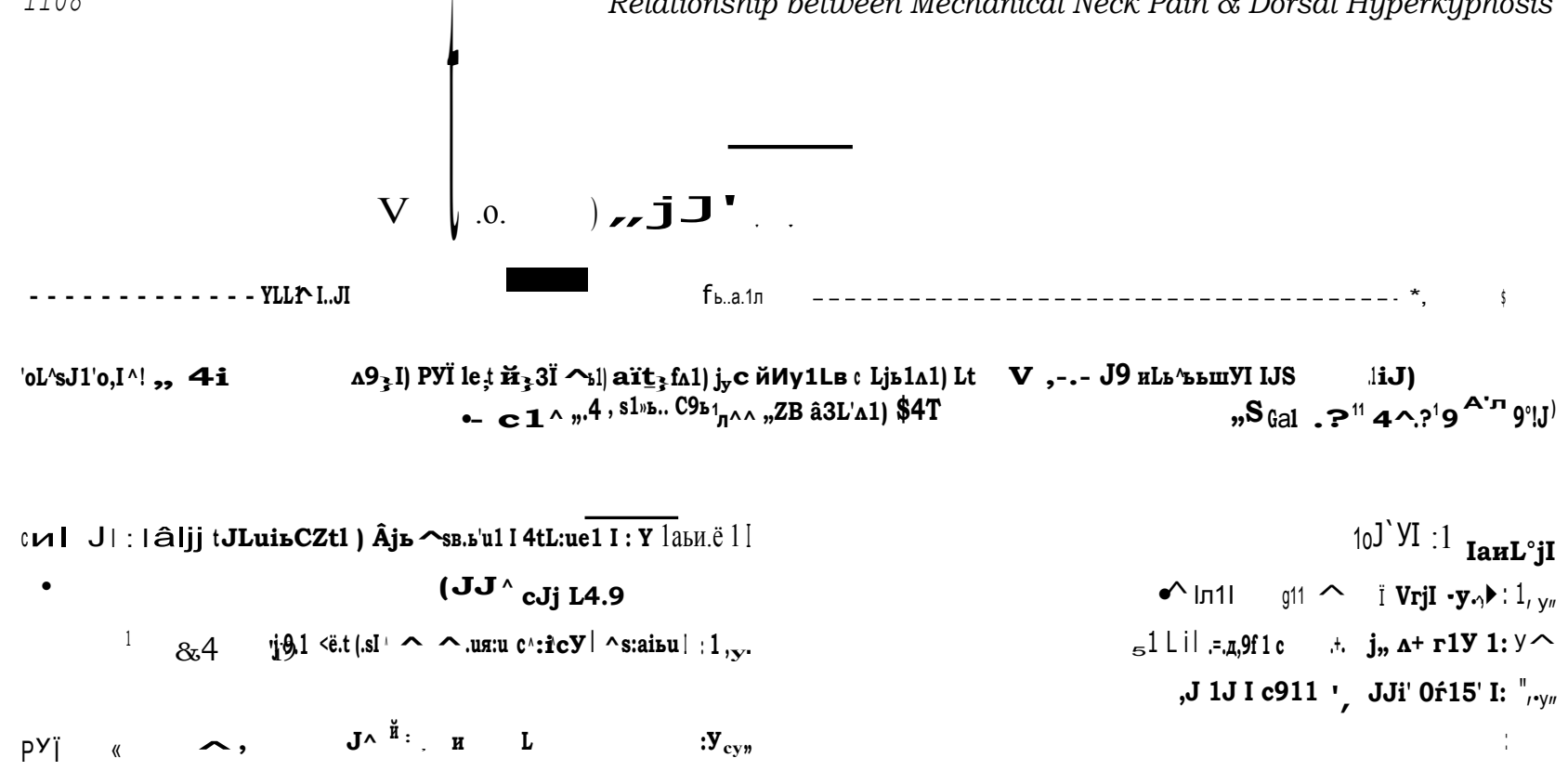

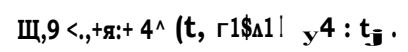

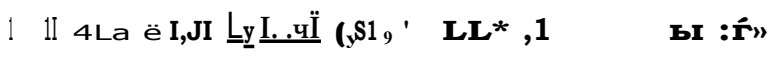

I c,яوl। Ij i, j 1 II :O. »

$0 . "$

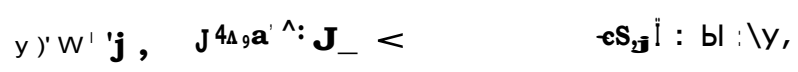

$: t$

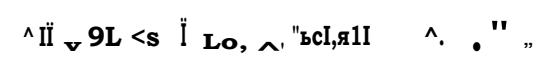

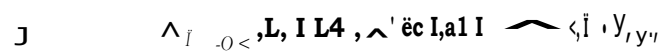

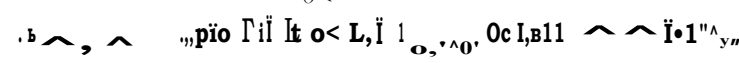

م 410..,,984.II ]2I n. :<.L, Ï L4, ,t4, ëc $111 \pm \leq$.

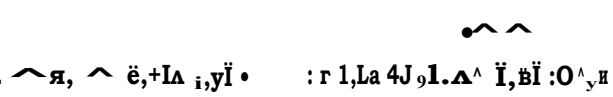

L

j5 :'1

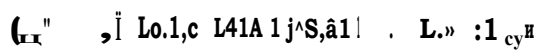

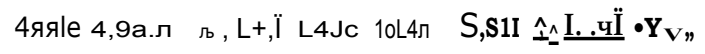

$1+, \ddot{I}$

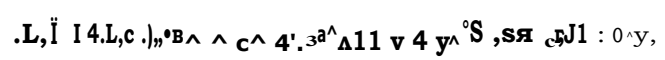
; iJ J! $\mathrm{JL}, \wedge_{\mathrm{J}} !$

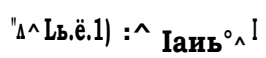

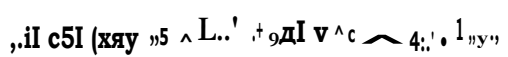

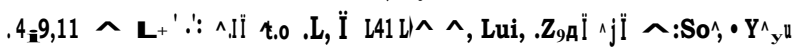

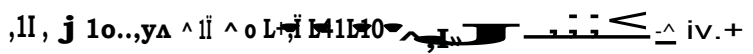

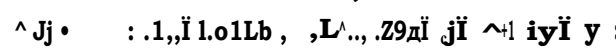

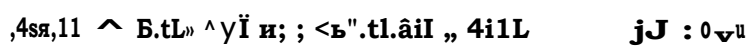

Lr9' jJ I :1" ^asPu.âJ I

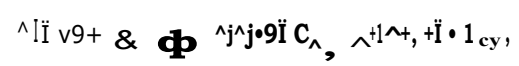

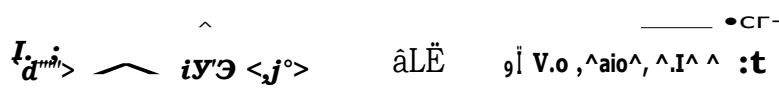
I3I

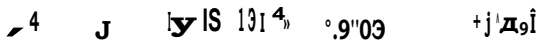

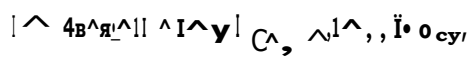
$\mathbf{y}: 1_{\mathrm{cj}}$ : $01 p, u b \hat{a} .11$ $., 11, \mathbf{j} \sim \mathbf{1}, \mathbf{-}_{c} \boldsymbol{c}, t i, \boldsymbol{c}, \boldsymbol{J}:$ $, \mathrm{tL}^{\prime} \quad, 10 \mathrm{iL} \mathrm{L}_{9} \mathrm{~L} \wedge \mathrm{I}, \ldots{ }_{\mathrm{C}} \mathrm{S} . \mathrm{ti}, \mathrm{c}: \boldsymbol{t}$ l' 'j.o yiS ^ ^l' leiu $9,0 \wedge I$ :.c, ,i,n :

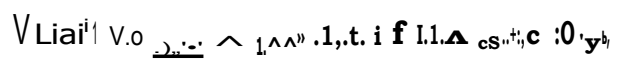

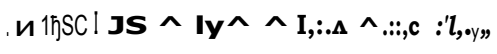
CJ.o.x11: V 1abL.â11 $1, \ddot{I} \quad$ L4,:B+Jos1I $\underline{\mathbf{t}}::_{\wedge: . .,} \ddot{I} \bullet 1_{\text {us }}$

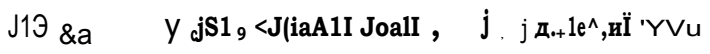

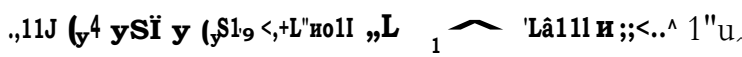

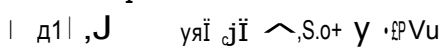

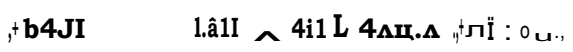

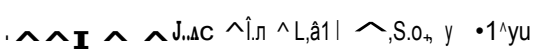


Ă^g^9rJ I ^у іi вввів. VI :1 •

Ы: $1, y$,

$. i^{\wedge} я, 1 I^{\wedge} \wedge . i і ̈$

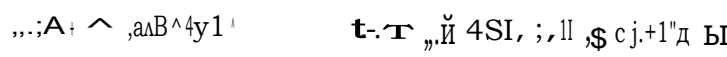

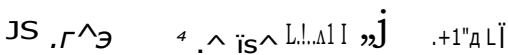

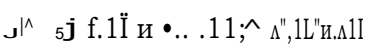

Ы

.i.я, 1 I I .1I

LSL, ^.I^яII <^ 4iIL 4^y..^ .tâ̂ bl

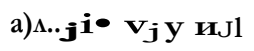

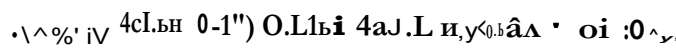

P $1^{\prime} . \wedge$ JS L. ;.0 L .J 'Y $1: 1$

$9: J=9$ 